\title{
Research on the Application of Materials in Interior Design Based on the Concept of Environmental Protection
}

\author{
Zou Ying \\ Hubei Three Gorges Polytechnic, Yichang, Hubei, 443000
}

Keywords: concept of environmental protection; interior design; application mode

\begin{abstract}
With the gradual improvement of living standard, people pay more and more attention to the healthy living conditions of ecology and naturalization. Indoor space as the main place where people live, the design of it is conducive to the gradual realization of organic integration with the concept of ecological design in the continuous development. Only in this way, can people live in indoor environment with better quality, and then promoting the quality of life of people in their development, which is beneficial for avoiding the previous problems in the interior design. Therefore, this paper mainly analyzes the problems existing in the current interior design, the principles and methods of interior design under the concept of environmental protection, so as to promote the continuous improvement of the quality of interior design in our country, thus promoting the improvement of people's quality of life.
\end{abstract}

\section{Introduction}

With the rapid development of social economy, people attach increasingly more attention to ecological protection and sustainable development in the process of development, whose reason is that the current environmental problems are becoming more and more serious. If effective measures do not be taken, especially in the interior design to protect environment, it will have a serious impact on people's lives and work. Since indoor space plays a main role in people's life, if it has serious environmental problems, it will affect people's normal life and work. Therefore, with the development of domestic design concept, in order to ensure that people have a good and ecological living environment, people gradually combine ecological design concept into interior design. The creation of ecological and sustainable indoor space environment is bound to become the mainstream trend of interior design. And in the process of continuous practice, perfection of the ecological interior design not only contributes to providing a healthy living environment for people, but also has great help to promote the sustainable development of the environment in our country, which is helpful to avoid the problems existing in the domestic interior design in the process of development.

\section{Problems in Current Interior Design}

Green indoor ecological design is an important part of ecological architecture research, but due to the influence of various subjective and objective factors, it has not been paid enough attention to by the construction industry and interior design industry. As a result, many problems exist in the development of interior design in the past.

Interior designers are usually design in accordance with the requirements of the customers. Some customers have very high requirements for their indoor environment, requesting their own indoor environment a certain sense of fashion that can not only reflect the elegant indoor environment, but also satisfy their self-vanity to a certain extent. Therefore, customers require excessive use of polished stone, glass, aluminum, marble, brocade and other fashionable luxury materials for design interior, which is a wrong design concept in fact. If Polished stone, glass, aluminum alloy, marble, brocade and other fashionable luxury materials made by using non-renewable are widely used in interior design, it will not only be inconsistent with the current concept of sustainable environmental development in China, but will also have a great impact on the healthy development of the architectural interior design industry, even hindering the sustainable development of the 
interior design industry ${ }^{[1-2]}$. Therefore, in order to avoid this situation, interior designers need to strictly control the use of fashionable, luxurious and novel design materials.

With the progress and development of the times, people's aesthetic concept has been promoted unprecedentedly. Consequently, interior design decoration generally adopts the most popular design style and decorative materials in the interior design work to conforms to the current aesthetic concept of people [3]. Although time-efficient materials have a good effect for indoor design aesthetic improvement, the style of interior design and decorative materials will be changed every few years because of the change of people's aesthetic concept. And the decorative materials used by people have the problem of being unable to recycle, so the indoor decoration materials which have been demolished due to the difference of aesthetic concept are discarded into construction garbage because they cannot be recycled. The emergence of this problem will not only lead to a crisis of serious pollution of our living environment, but also cause serious waste of resources in our country, seriously impeding the future progress of the concept of sustainable development in China.

\section{Principles of Interior Design Under the Concept of Environmental Protection}

As a result of the above problems, if people do not make corresponding improvements in the design work in the course of development but continue to use design materials that will have an impact on the environment, it will lead to the continuous environmental deterioration in the process of development of our country. Therefore, with the continuous promotion of environmental protection and the formation and development of the concept of environmental protection in our country, the concept of environmental protection has been gradually integrated into the interior design work and our own development principles for the corresponding development are adhered to in the process of promoting the development of interior design industry.

The most important requirement in the concept of environment-friendly interior design is to keep human health. The interior design work carried out by interior designers keeps a main goal serving people's indoor home life, so that, interior designers work with a certain health index will be helpful to maintain a certain level of stability of health for people during their development, conducive to the health of them. At the same time, interior designers shall satisfy people's aesthetic standards and requirements as well as promote the level of people's mental health to a certain extent in the interior design, thus giving people a relaxing and pleasant atmosphere rather than repressing and desolate atmosphere [4-5]. Therefore, interior design work adheres to the people-centered principle, which is good for both the promotion of the physical health of people and the improvement of people's mental health problems. In the meanwhile, the natural environmental protection function must be included in the ecological interior design, that is, to minimize the pollution of the chemical, physical and other factors to the living environment in the design. Different from the current situation, many harmful chemicals and construction waste damage to the living environment, interior design work surrounding the main principle of environmental protection plays a great role in promoting the continued work of environmental protection.

Under the influence of the concept of environmental protection, the interior design work pays more attention to human safety and health, freedom awareness and human nature requirements as well as the performance of nature protection in its development. The environment-friendly interior design work realizes the human friendly design which diligently pursues the idea that man is a member of the nature, but not a master of all things that is kept in accordance with to endeavor to avoid harm to nature[6]. Therefore, in order to promote the smooth development of the current interior design work, it is necessary to adhere to the main development goal of the harmonious development of man and nature to conduct corresponding development under the influence of the concept of environmental protection. If nature is to be compared to the mother of man, it is necessary to absorb nutrients from Mother Nature to promote human progress and development. However, in order to avoid the excessive demand for Mother Nature's nutrients, which makes Mother Nature unable to develop healthily, people need to obtain appropriate limited nutrients to promote the harmonious development of human and nature. 


\section{The Way of Interior Design under the Concept of Environmental Protection}

Reasonable space layout can not only ensure good ventilation, reasonable partition and sufficient light, but also reasonably conceal some problems and highlight some advantages in indoor space by adjusting the visual differences in the process of layout, to continuous improve the interior design quality[7]. Therefore, in order to meet the requirements of natural ventilation, interior designers can adopt a relative open ecological layout in their work. And part of the wall can also be properly removed to expand the indoor space to a certain degree to make it broader and brighter, and to benefit the environment-friendly indoor design. In order to do a good interior design under the concept of environmental protection, it is necessary to take a reasonable and effective way to layout the indoor environment where customers live, which is conducive to improve the customer's satisfaction with the interior design.

In general, people have very high requirements for lighting conditions in their lives, so in order to ensure sufficient lighting in their own indoor environment, indoor lighting should be well designed. Indoor lighting design mainly includes sunshine conditions, artificial lighting and natural lighting, among which natural lighting has a great role in promoting the development of people. Natural lighting, generally the sunlight, if it is applied as far as possible to obtain more illumination in the design of indoor lighting, it is helpful to improve the quality of users' daily life and promote the development of green environmental protection to a certain extent at the same time[6]. Therefore, in order to make full use of sunlight, interior designers need to introduce natural light through a large area of glass into the interior. Then during the corresponding work, the accurate calculation of local sunshine time, solar azimuth and indoor sunshine area should be done, and the space between buildings should also be taken into account. Only in this way, can the natural atmosphere of indoor space be guaranteed to be improved in the design of indoor lighting conditions, to ensure the development quality of people. Interior designers should design indoor artificial lighting from the angle of energy saving and environmental protection, and place relatively simple lighting lamps to meet the basic indoor lighting, so as to ensure the sense of comfort of people in daily life.

\section{Conclusion}

In conclusion, in order to avoid the problems of excessive pursuit of fashionable, luxurious and novel interior design and serious waste of interior design materials in the interior design work, it is necessary to make environment-friendly interior design to carry on the corresponding work in accordance with the concept of environmental protection. And during the design, the reasonable layout of indoor space and the suitable design of indoor lighting should both be done. Only in that way can the sustainable development of interior design under the concept of environmental protection in our country be promoted.

\section{References}

[1] Zhang Wei. Application of Interior Decoration Materials Based on Ecological Concept[J]. Building Materials \& Construction \& Decoration, 2017, 8(7): 42.

[2] Teng Yunfei. Application of Ecological Concept in Interior Design[J]. Exam Weekly, 2014, 20(58): 161-162.

[3] Xu Cheng. Analysis on the Application of Interior Decoration Materials Based on the Idea of Environmental Protection[J]. Real Estate Biweekby, 2015, 20(28): 25.

[4] Chen Dongcai. Application of Environmental Protection Concept in Interior Decoration Engineering[J]. Fujian Building Materials, 2011, 5(2): 35-36.

[5] Luo Weqiang. On the Application of Ecological Materials in the Interior Decoration of Home[J]. Modern Decoration (Theory), 2015, 5(5): 20. 
[6] Gao Xuan. Analysis on the Application of Green Environmental Protection in Interior Decoration and Design[J]. The Merchandise and Quality, 2016, 10(24): 25.

[7] Du Qiurong. Analysis on the Application of Green Environmental Protection in Interior Decoration Design[J]. Sichuan Cement, 2015, 4(8): 126.

[8] Lu Congna, and Wang Li. Application of Green Environmental Protection Concept in Interior Space Design[J]. Modern Decoration(Theory), 2016, 1(2): 30. 